NAT'L INST OF STANDARDS \& TECH R.I.C.

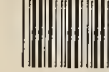

A11102490992 Jones, Walter W/Buoyancy drlven flow as
QC100.U56 NO.86-3329 1986 V19 C.1 NBS-P

\title{
Buoyancy Driven Flow As the Forcing Function of Smoke Transport Models
}

Walter W. Jones

Xavier Bodart

U.S. DEPARTMENT OF COMMERCE

National Bureau of Standards

National Engineering Laboratory

Center for Fire Research

Gaithersburg, MD 20899

May 1986

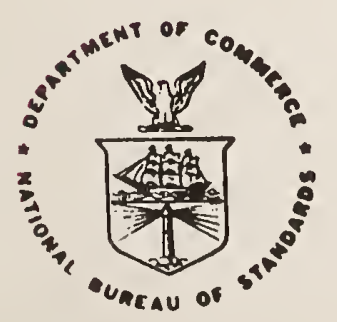

U.S. DEPARTMENT OF COMMERCE

$-Q C$ INAL BUAEAU OF STANDARDS

100

.456

86-3329 

NBSIR 86-3329

$\cdots$

BUOYANCY DRIVEN FLOW AS THE FORCING FUNCTION OF SMOKE TRANSPORT MODELS

Walter W. Jones

U.S. DEPARTMENT OF COMMERCE

National Bureau of Standards

National Engineering Laboratory

Center for Fire Research

Gaithersburg, MD 20899

USA

and

Xavier Bodart

Centre Scientifique et Technique du Batiment

Champs Sur Marne

France

May 1986

U.S. DEPARTMENT OF COMMERCE, Malcolm Baldrige, Secretary NATIONAL BUREAU OF STANDARDS, Ernest Ambler, Director 



\section{$\underline{\text { Page }}$}

LIST OF FIGURES $\ldots \ldots \ldots \ldots \ldots \ldots \ldots \ldots \ldots \ldots \ldots \ldots \ldots \ldots \ldots \ldots \ldots \ldots \ldots$

LIST OF TABLES $\ldots \ldots \ldots \ldots \ldots \ldots \ldots \ldots \ldots \ldots \ldots \ldots \ldots \ldots \ldots \ldots \ldots \ldots \ldots$

Abstract $\ldots \ldots \ldots \ldots \ldots \ldots \ldots \ldots \ldots \ldots \ldots \ldots \ldots \ldots \ldots \ldots \ldots \ldots \ldots \ldots \ldots \ldots$

1. INTRODUCTION $\ldots \ldots \ldots \ldots \ldots \ldots \ldots \ldots \ldots \ldots \ldots \ldots \ldots \ldots \ldots \ldots \ldots \ldots \ldots \ldots$

2. PROBLEM TO BE SOLVED .............................. 2

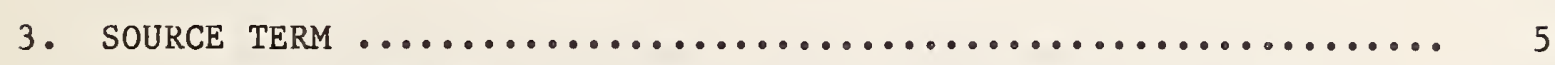

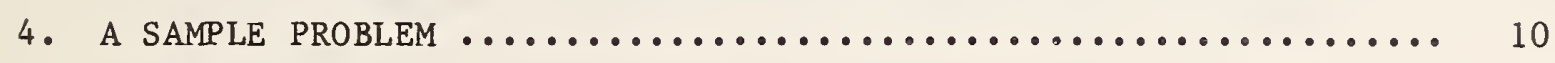

5. CONCLUSIONS $\ldots \ldots \ldots \ldots \ldots \ldots \ldots \ldots \ldots \ldots \ldots \ldots \ldots \ldots \ldots \ldots \ldots \ldots \ldots \ldots$

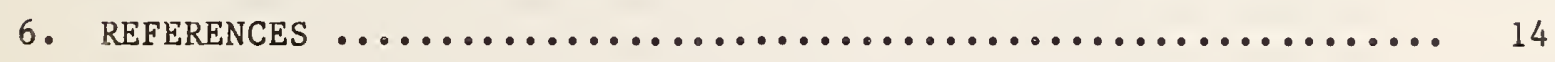


Figure 1. Typical flow patterns through vents which are subjected

to fires ................................... 15

Figure 2. Pictoral of the integration scheme used in eqn. (7) .... 16

Figure 3. Schematic of the notation used in the source term

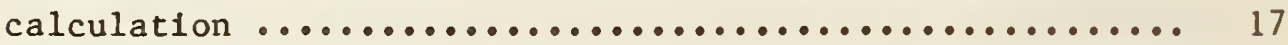

Figure 4. A subset of the flows of class I; see Table I ........ 18

Figure 5. An example of the effect which change in the interface height will cause for one of the diagrams in Fig. $4 \ldots . . .19$

Figure 6. Output from the pressure function evaluation at 0,20 , 40 and 60 seconds. The surface plot shows the actual values and the contours are: yellow: $\mathrm{df} / \mathrm{dt}=0$; green and red: $\mathrm{df} / \mathrm{dt}= \pm \delta$. Pressure variation is left to right on the diagram and temperature variation is into the picture (upper left figure) ................... 20

Figure 7. Data capture "on-the-fly" from the function evaluation from 49 to 51 seconds (upper right figure) ........... 20

Figure 8. A composite of the output of the function evaluation from 0 to 60 seconds (bottom of page) ............... 20 
LIST OF TABLES

Page

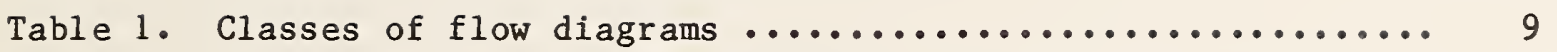

Table 2. Condition used to separate and order the flow diagrams ... 11 

BUOYANCY DRIVEN FLOW AS THE FORCING FUNCTION OF SMOKE TRANSPORT MODELS

Walter W. Jones

Xavier Bodart

Abstract

Flow at vents is the major driving force in smoke transport models. The precision with which we can calculate these flows determines to a great extent how accurately we can model buoyant flow and the inherent speed of the models. This report describes some of the problems encountered in calculating these flows, and gives a general algorithm for their calculation.

Key words: vent flow, smoke transport model, fire modeling, differential equation.

\section{INTRODUCTION}

Over the past few years modeling fire growth and smoke transport has become an important aspect of fire research. As computers have become cheaper and faster, the ability to handle the equations associated with such phenomena has improved to the point where numerical experiments can replace some physical experiments. This is useful in avoiding the expense and effort of actual fire tests. To this end there are two aspects of modeling which are important. The first is that the physical algorithm must be correct and the second is that the numerical routines which are utilized must be fast and able to handle the wide range of values which occur in natural phenomena. Typical time scales range from microseconds for chemical kinetics to tens of seconds for heat conduction. 
The predictive equations which are solved arise from the conservation of mass, momentum and energy. When integrated over a finite sized control volume, they are first order, nonlinear, ordinary differential equations, of the form

$$
\frac{d x}{d t}=f(x)
$$

where $x$ represents a vector of unknown dependent variables. Much of the modeling has assumed a simplification which is to solve the pseudo steadystate as the transient term vanishes

$$
\frac{d x}{d t}=f(x)+0
$$

In either case a solution is found by varying $x$ in the phase space about some initial value $x_{0}$ and looking for a minimum in the value of the function $f(x)$ or actually $\left\{\frac{d x}{d t}-f(x)\right\}$. The thesis of this paper is the difference in the physical meaning of these two types of equations and to demonstrate that solving the original ODE's is superior to solving their algebraic counterpart. The underlying point is to demonstrate the rationale that the apparenty more complex form of the equations is actually easier to solve, and in addition to show that the algebraic form may not always yield the correct solution.

\section{PROBLEM TO BE SOLVED}

The difficulty which arises in the solution of eqn. (1) is the bumpiness in the multidimensional phase space allowed by these equations (one for each zone or control volume). The term "phase space" is used in this context to 
mean the manifold of pressure, temperature, etc., in which the solution of the relevant set of equations lie, and the possible physical variations which can occur. Even for a single equation, e.g. the pressure equation, the topology is not simple. There is an assumed simplification of considering only relaxed states $\frac{\mathrm{dx}}{\mathrm{dt}}=0$ which can actually make achieving the final state more difficult. No direction is provided in finding a minimum and it gives no sense of whether a specific bump in the manifold is an absolute minimum. By retaining the transient term some relief is obtained for this situation. The most important improvement in finding a solution is that search direction in phase space is given by the transient term. Thus the basic search algorithm is considerably simplified. The second bit of help comes from the observation that the derivative terms do not vanish at a pseudo minimum but only at absolute minimum. Further, the point for which the transient term vanishes may not be the correct solution. The correct solution actually minimizes the difference between the left and right side of eqn. (1).

Several examples should serve to illustrate the problem, a possible solution and the means by which this translates into a technique for a general solution of the equations.

The actual equations which we solve are somewhat more complex than eqn. (1); however, it is useful to use a simplified example to test the techniques. Then one can test the heuristic without getting bogged down in technical details of numerical programming. The set of predictive equations which we use for each compartment in a typical zone model [1], are

$$
\frac{\mathrm{dP}}{\mathrm{dt}}=\frac{\dot{\mathrm{s}}}{(\beta-1) \mathrm{V}}
$$




$$
\begin{aligned}
& \frac{d T_{u}}{d t}=\frac{1}{\beta}\left(\frac{T_{u}}{P V_{u}}\right)\left(\dot{E}_{u}+\frac{V_{u}}{(\beta-1)} \dot{s}\right) \\
& \frac{d T_{\ell}}{d t}=\frac{1}{\beta}\left(\frac{T_{\ell}}{P_{\ell}}\right)\left(\dot{E}_{\ell}+\frac{V_{\ell}}{(\beta-1)} \dot{s}\right) \\
& \frac{d V_{u}}{d t}=\left(\frac{1}{P \beta}\right)\left({ }_{p} m_{u} T_{u}+\dot{E}_{u}-\frac{V_{u}}{V} \dot{s}\right)
\end{aligned}
$$

where

$$
\dot{s}=c_{p} \dot{m}_{u} T_{u}+c_{p} \dot{m}_{\ell} T_{\ell}+\dot{E}_{u}+\dot{E}_{\ell}
$$

and

$$
\beta=c_{p} / R=\gamma /(\gamma-1)
$$

where $\mathrm{T}$ is the temperature and $\dot{\mathrm{E}}_{\mathrm{u}}$ and $\dot{\mathrm{E}}_{\ell}$ are the energy release rates into the upper and lower zones, respectively. The primary source term is the $\dot{s}$ which depends mainly on fluid transport, that is enthalpy flux driven by density and pressure gradients. It also varies the most rapidly. Actually, the microscopic chemical kinetics have a shorter time constant but the spatially averaged zone properties $(T, \rho)$ do not vary on such a time scale and thus it is reasonable to ignore these very short times. In addition to improving the solution technique itself, we have developed a better method of finding the dominant portion of the source term, $\dot{m}$, the enthalpy flux from mass flow. Due to its importance, we will discuss it in the next section before giving examples of the solution of this type of problem.

The conservation equations which we solve are for energy and mass. Momentum is not defined within a control volume but only at the boundaries where zones are connected. So we do not solve the momentum equation directly 
but rather use the integral form known as Bernoulli's equation which yields mass flux as a function of the pressure and density differences.

\section{SOURCE TERM}

Equation (2) is the one on which we shall focus as it is this one that is most often "simplified" in the asymptotic sense. In order to explain some of the difficulty encountered in solving this equation, we digress for a moment to discuss the primary source term, namely fluid transport through vents.

This fluid flow phenomenon connects the control volumes and is dominant because this term fluctuates most rapidly of all the source terms in response to changes in the environment. One of the improvements which we have incorporated into our current models is a means of calculating these flow fields with the correct number of neutral planes (up to three) and without discontinuties in the function. This latter feature implies no discontinuities in the first order derivatives for the ODE's.

Typical types of flows which can occur in fires are illustrated in fig. 1. The notation for the flow is

$$
\begin{aligned}
& \mathrm{SS}=\text { upper layer to upper layer } \\
& \mathrm{SA}=\text { upper layer to lower layer } \\
& \mathrm{AS}=\text { lower layer to upper layer } \\
& \mathrm{AA}=\text { lower layer to lower layer }
\end{aligned}
$$


This notation was originated earlier [2] for the single neutral plane case but is useful for a physical description of the general problem. One generally uses the Bernoulli equation to calculate the flow velocities between two compartments which are connected by an opening. Indeed this is the solution for the momentum equation which allows us to exclude it specifically when solving the conservation equations in general.

The general form is

$$
\dot{\mathrm{m}}_{\text {io }}=\mathrm{C} \cdot \mathrm{s} \cdot \sqrt{2 \rho\left|\mathrm{P}_{\mathrm{i}}-\mathrm{P}_{\mathrm{o}}\right|}(\mathrm{kg} / \mathrm{sec}) \text {, }
$$

$$
\text { where } \begin{aligned}
\dot{\mathrm{m}} & =\text { mass flow rate } \\
\mathrm{C} & =\text { orifice coefficient } \\
\mathrm{S} & =\text { opening area }\left(\mathrm{m}^{2}\right) \\
\rho & =\text { gas density on side " } \mathrm{l} " \\
\mathrm{P}_{i} & =\text { pressure on side " } i " \\
\mathrm{P}_{0} & =\text { pressure on side "o". }
\end{aligned}
$$

The implication of using this equation is that the pressure at a stagnation point is used. That is, the flow velocity vanishes where the pressure is measured. As the pressure always appears as a difference, in principle $1 t$ does not matter whether absolute pressures or pressure defects are used. More accuracy is obtained by using pressure defect, however. This avolds, to some extent, the problems of the small difference of large numbers.

The pressure is always calculated with respect to the base of a compartment. With this in mind we can express the pressure on the other 81 de of a 
partition as a function of the variable (y), the height above the base:

implicit in our use of equation (6) is that the opening is rectangular, so that the area integral of the flow term will allow us to remove the width from the integral.

That is

$$
\text { flow }=\int_{\text {width }} \int_{\text {height }} \rho V d z d b \rightarrow \text { width } \int_{1}^{Z_{2}} \rho V d z \text {. }
$$

Thus the total flow becomes

$$
\dot{\mathrm{m}}_{i \rightarrow 0}=\mathrm{CW} \sum_{\mathrm{k}} \mathrm{S}_{\mathrm{k}} \sqrt{2 \cdot \rho_{\mathrm{i}, \mathrm{k}}\left|\mathrm{P}_{\mathrm{i}}(\mathrm{z})-\mathrm{P}_{\mathrm{o}}(\mathrm{z})\right|} .
$$

The pressure term will be reversed if the flow is $0 \rightarrow i$. Thus we have the integral over the area shown in fig. 2. Terms are as before except that $\rho_{i, k}$ is the average inlet mass density within area "k". The simplest way to define the limits of integration is with neutral planes, that is the height at which flow reversal occurs, $P_{i}(z)=P_{0}(z)$.

Each side of an opening is assumed to consist of two homogeneous gas layers (zones) of uniform density and temperature. There is an apparent inconsistency in that the equation of state dictates $P=\rho R T$, and we assume $P^{\circ}$ varies but $\rho$ and $T$ remain constant, at least within a zone. This pressure fluctuation is so small compared to the magnitude of the base pressure that ignoring it for all calculations except the flow field is reasonable. For simplicity of notation we will use a slightly different means of identifying the zones. The correspondence is 


$$
\begin{aligned}
& \text { upper "1" zone }=1 \\
& \text { lower " } 1 \text { " zone }=2 \\
& \text { upper "o" zone }=3 \\
& \text { lower " } 0 \text { " zone }=4
\end{aligned}
$$

The former term using "SA" is physically more understandable and the results can be put into these terms, but the derivations are more compact with the numerical indicies. Figure 3 shows a schematic of the notation. The corresponding densities are $\rho_{1}, \rho_{2}, \rho_{3}$ and $\rho_{4}, B_{f}, H_{f}, Z_{1}$ and $Z_{0}$ are the height of a sill, soffit, hot/cold interface in the " 1 " compartment and hot/cold interface in the "o" compartment. With the base (reference) pressures $P_{1}(0)$ and $P_{0}(0)$, the internal pressure on each side is given by

$$
\begin{aligned}
& P_{1}(z)=P_{1}(0)-\min \left(y, z_{1}\right) \cdot \rho_{2} g-\max \left(z-z_{1}, 0\right) \cdot \rho_{1} g \\
& P_{0}(z)=P_{0}(0)-\min \left(y, z_{0}\right) \cdot \rho_{4} g-\max \left(z-z_{0}, 0\right) \cdot \rho_{3} g
\end{aligned}
$$

The function $F(z)=P_{1}(z)-P_{e}(z)$ can be considered a famlly of functions of one variable, $z$. In all cases the pressure appears only in this form. In principle, this family of curves can lead to an inordinate number of possible flow fields. By imposing the restrictions found in fire scenarios, however, we end up with only a few possiblities. For stratification to occur, the following restrictions can be imposed:

$$
\begin{aligned}
& \rho_{1} \leq \rho_{2} \\
& \rho_{3} \leq \rho_{4} .
\end{aligned}
$$


We can also require

$$
\rho_{1} \leq \rho_{3}
$$

without loss of generality, since for the reverse, it is only necessary to reverse the " $i$ " and " $o$ " compartments. We are left with five different cases. These cases and their restrictions are shown in Table I.

\section{TABLE I}

Class Restrictions

Max 非 of neutral planes

1

2

3

2

1
Figure 4

a

b

c

d

e

Classification of types of flow which occur in a vent based on the relative densities and interface heights. If there exist soffits or sills, then the number of neutral planes within a vent can be less than the number indicated.

If there were no soffits or sills to consider, then the calculation would be fairly straightforward. However, the possibility of soffit/sill combinations requires many numerical tests in the calculation. Class I is the basis of the analysis of classes II-V. It can have 44 different flow combinations, depending on the relative position of $\mathrm{H}_{f}, \mathrm{~B}_{\mathrm{f}}, \mathrm{Z}_{i}$ and $\mathrm{Z}_{\mathrm{o}}$. It may contain at most a single neutral plane (flow reversal). Twenty four of these combinations are without a neutral plane and twenty with a neutral plane. Figure 5 shows the effect of the "o" compartment interface height on the flow field from one of the diagrams shown in Figure 4. 
Table II shows the criterią used for solution in classes II-V. The interval $\left[\mathrm{B}_{\mathrm{f}}, \mathrm{H}_{\mathrm{f}}\right]$ can subsequently be partitioned to contain at most a single neutral plane so that the logic used for class I can be utilized. The only caveat is to be sure that the equalities and inequalities are treated correctly.

\section{A SAMPLE PROBLEM}

We limit our discussion to eqn. (2) with the appropriate source terms. It is most of ten this equation to which the asymptotic approximation is applied, namely

$$
\frac{d P}{d t}=\frac{\dot{s}}{(\beta-1) V} \rightarrow 0
$$

This approximation is appropriate for a steady state situation, for example, where a fire is fully developed and the flow fields have been established. For a transient problem such as a developing fire or the case when a window 1s broken, such is not appropriate. Most models of fire 1 mply this approximation by using large initial time steps, perhaps of one or two seconds. However, when faced with a true transient phenomenon, all sub-divide the time step, generally to a value below the pressure relaxation time.

Furthermore, a fundamental problem arises in that the solution for eqn. (2) may not be identical to that of eqn. (8). The requirement is that the difference between the left- and right-hand sides (LHS and RHS) of the conservation equations should be minimal. This is truly equivalent to the statement of eqn. (8) only in a steady state regime. So this approximation 


$$
F(z)=P_{i}(z)-P_{e}(z)
$$

Max. no. of neutral planes in $\left[\mathrm{B}_{\mathrm{f}}, \mathrm{H}_{\mathrm{f}}\right]$

II. $Z_{i} \leq B_{f}$

0,1

$\mathrm{Z}_{\mathrm{i}} \geq \mathrm{H}_{\mathrm{f}}$

0,1

$$
\begin{aligned}
B_{f}<Z_{i}<H_{f} & \\
F\left(Z_{i}\right) & \max \left(F\left(B_{f}\right), F\left(H_{f}\right)\right) \geq 0 \\
F\left(Z_{i}\right) \cdot & \max \left(F\left(B_{f}\right), F\left(H_{f}\right)<0\right. \\
& F\left(Z_{i}\right): \min \left(F\left(B_{f}\right), F\left(H_{f}\right)\right) \geq 0 \\
& F\left(Z_{i}\right) \cdot \min \left(F\left(B_{f}\right), F\left(H_{f}\right) \leq 0\right.
\end{aligned}
$$

III. $\mathrm{z}_{\mathrm{i}} \geq \mathrm{H}_{\mathrm{f}}$

$$
\mathrm{Z}_{\mathrm{o}} \leq \mathrm{B}_{\mathrm{f}}, \mathrm{Z}_{\mathrm{i}} \geq \mathrm{H}_{\mathrm{f}}
$$

$\mathrm{Z}_{\mathrm{o}} \leq \mathrm{B}_{\mathrm{f}}, \mathrm{Z}_{\mathrm{i}} \leq \mathrm{B}_{\mathrm{f}}$

$$
\mathrm{Z}_{\mathrm{o}} \leq \mathrm{B}_{\mathrm{f}}, \mathrm{B}_{\mathrm{f}}<\mathrm{Z}_{\mathrm{i}}<\mathrm{H}_{\mathrm{f}}
$$

$$
\begin{aligned}
F\left(Z_{i}\right) \cdot & \max \left(F\left(B_{f}\right), F\left(H_{f}\right)\right) \geq 0 \\
F\left(Z_{i}\right) \cdot & \max \left(F\left(B_{f}\right), F\left(H_{f}\right)\right)>0 \\
& F\left(Z_{i}\right): \min \left(F\left(B_{f}\right), F\left(H_{f}\right)\right) \geq 0 \\
& F\left(Z_{i}\right) \cdot \min \left(F\left(B_{f}\right), F\left(H_{f}\right)\right) \leq
\end{aligned}
$$

$$
\begin{aligned}
& \begin{aligned}
\mathrm{B}_{\mathrm{f}}<\mathrm{Z}_{\mathrm{o}}<\mathrm{H}_{\mathrm{f}} \\
\mathrm{Z}_{\mathrm{i}} \geq \mathrm{H}_{\mathrm{f}}
\end{aligned} \\
& F\left(Z_{o}\right) \cdot \min \left(F\left(B_{f}\right), F\left(H_{f}\right)\right) \geq 0 \\
& F\left(Z_{o}\right) \max \left(F\left(B_{f}\right) \cdot F\left(H_{f}\right)\right)>1 \\
& \mathrm{~F}\left(\mathrm{Z}_{\mathrm{o}}^{\mathrm{o}}\right) \cdot \max \left(\mathrm{F}\left(\mathrm{B}_{\mathrm{f}}\right), \mathrm{F}\left(\mathrm{H}_{\mathrm{f}}\right)\right)^{\circ} \leq 0 \quad 2 \\
& Z_{i}<H_{f}\left[B_{f}<Z_{j}{ }^{\circ}<Z_{j}<H_{f}\right] \max \left(F\left(H_{f}\right), F\left(Z_{\rho}\right)\right)>00 \\
& \left.\min \mathrm{F}_{1}\left(\mathrm{~B}_{\mathrm{f}}\right), \mathrm{F}\left(\mathrm{Z}_{\mathrm{i}}\right)\right) \cdot \max \left(\mathrm{F}\left(\mathrm{H}_{\mathrm{f}}\right), \mathrm{F}\left(\mathrm{Z}_{\mathrm{o}} \rho\right) \geq 01,2 \text { or } 3\right.
\end{aligned}
$$

IV. $\mathrm{Z}_{\mathrm{i}} \geq \mathrm{H}_{\mathrm{f}}$

$$
0,1
$$

$\mathrm{Z}_{\mathrm{i}} \leq \mathrm{B}_{\mathrm{f}}$

0,1

$$
\begin{aligned}
& B_{f}<Z_{i}<H_{f} \max \left(F\left(B_{f}\right), F\left(H_{f}\right)\right) \geq 0 \\
& F\left(Z_{i}\right) \geq \max \left(F\left(B_{f}\right), F\left(H_{f}\right)\right)<0 \\
& F\left(Z_{i}\right) \cdot \max \left(F\left(B_{f}\right)\right. F\left(Z_{i}\right): \min \left(F\left(B_{f}\right), F\left(H_{f}\right)\right)>0 \\
& F\left(Z_{i}\right) \cdot \min \left(F\left(B_{f}\right), F\left(H_{f}\right)\right) \leq 0
\end{aligned}
$$

V. $F$ is monotonic over $\left[B_{f}, H_{f}\right]$ 
should only be made if there is a real gain, such as reduced computing requirements or equations which are simpler to manipulate. An example should 1llustrate some of the difficulties.

The context of a problem which we will examine is a four compartment calculation using the FAST [1] model to find a solution. The point of interest is to examine the solution of eqn. (2) in the second compartment. There are three ways to examine the equation: first, a pseudo analytic technique is to start with the converged solution of temperature and pressure in all compartments and then form a perturbation expansion of the RHS of eqn. (2), in terms of pressure and temperature for compartment $\# 2$ on $1 y$. The result is shown in fig. (6) as a surface plot of the value of the PHS of eqn. (2) for a variation in pressure (left to right) and temperature (into the picture). The total calculation lasts 60 seconds and fig. $(6 a, 6 b, 6 c$, and $6 d$ ) are done at $0,20,40$, and 60 seconds, respectively. The vartation in pressure was $\mathrm{P}_{0} \pm 0.8 \mathrm{kPa}$ and temperature $\mathrm{T}_{\mathrm{O}} \pm 100 \mathrm{~K}$. If this equation were solved by itself, then the solution would come fairly easily and eqn. ( 8 ) might be appropriate; second, we can capture the results from the ODE solver which is used in FAST. This was done at $50 \pm 1$ seconds and the results are shown in fig. (7). The axes are the same as in fig. (6). The latter flgure shows the somewhat more complex interaction of all sixteen equations, since we capture the intermediate results with variations in all parameters. From the figure it can be seen that it may not be possible to get from a pseudo minlmum on the left hand side to the correct answer on the right hand side using eqn. (8). Equation (2) helps by providing a direction and distance for subsequent solutions, namely the $\mathrm{dP} / \mathrm{dt}$ term, the term which has been dropped in the asymptotic approximation. Figure (8) shows a composite of the result of 
applying the second technique to the entire time history of the pressure equation.

Finally we can look at a simple piece of this problem analytically. We can extend earlier work on pressure relaxation. Attention is directed to fig. (1) and eqn. (28) in the paper by Rehm and Baum [3]. Two similar examples can be given, the first being the forced flow in the initial stages of a fire. For this case, expansion in the room of fire origin forces air into an adjacent compartment. For this case, eqn. (2) becomes $\left(\mathrm{P}^{\prime}=\mathrm{P}_{1}-\mathrm{P}_{3}\right)$

$$
\frac{1}{\mathrm{P}^{\prime}} \frac{\mathrm{dP}}{\mathrm{dt}}=\frac{1}{(\beta-1) \mathrm{V}} \mathrm{C}_{\mathrm{P}} \mathrm{C}_{\mathrm{d}} \delta \mathrm{T} \rho^{3 / 2} 2^{1 / 2} \mathrm{P}_{\mathrm{o}}^{-1 / 2}
$$

with $\mathrm{P}_{0}=\mathrm{P}_{i}(t=0)$. If the asymptotic approximation were correct then the right hand side would be constant for an e-folding time for $\mathrm{P}^{\prime}$. Integrating this equation, we find a characteristic time for the pressure equation is

$$
\tau \propto \frac{V}{2 A \delta T}
$$

where $\mathrm{V}$ is the volume of the compartment of interest, $\mathrm{A}$ is the vent opening and $\delta T$ is the temperature difference between the two compartments. For typical initial conditions we obtain a time constant about 1 second, but it can vary over a wide range. This is certainly not less than the typical time step used for the algebraic solver in fire models. The other extreme would be a near steady state regime of equal inflow and outflow. In this case, the equation reduces to

$$
\frac{\mathrm{dP}}{\mathrm{d} t}=\simeq 10^{7} \frac{\mathrm{A}}{\mathrm{V}} \mathrm{H}^{1 / 2} \frac{(\delta \mathrm{T})^{1 / 2}}{(\mathrm{RT})^{2}} \mathrm{P}^{3 / 2}
$$


where $R$ is the gas constant. For typical values of the parameters, this equation has a time constant of about 0.10 seconds, once again being within the range of times used in solving the other conservation equations.

\section{CONCLUSIONS}

We have tried to indicate where the problems arise in solving the conservation equation used in predicting fire growth and smoke spread. The type of predictive equations used and the primary driving term have been discussed in detail. Finally, a sample calculation has been presented to show where the problems actually exist for equation solvers and the reason that an ODE solver, in general, has an easier job in threading its way through the phase space thicket than does an algebraic solver. Experience has shown [4] that this method yields a reduction in computing time of a factor of two to an order of magnitude over the time required for a model wherein the asymptotic approximation has been made.

\section{REFERENCES}

[1] Jones, W.W., A Multicompartment Model for the Spread of Fire, Smoke and Toxic Gases, Fire Safety Journal $\underline{9}, 55$ (1985).

[2] Tanaka, T., A Model on Fire Spread in Small Scale Buildings, BRI (Japan) Research Paper 79 (1978).

[3] Rehm, R.G. and Baum, H.R., The Equations of Motion for Thermally Driven Buoyant Flows, Journal of Research 83297 (1978).

[4] Jones, W.W., An Improved Numerical Method for Fire Models, Fall Technical Meeting of the Combustion Institute, Atlantic City (1982). 


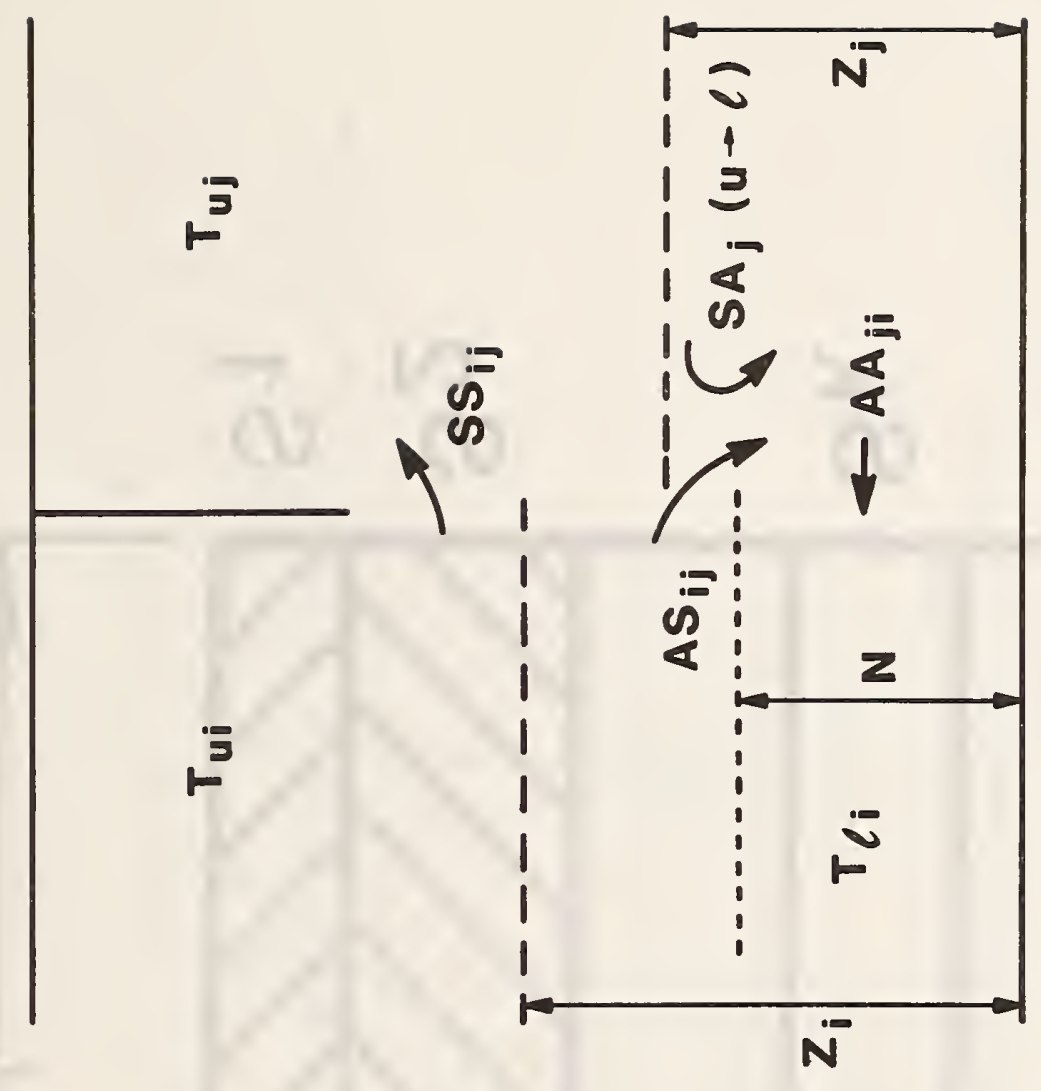

음

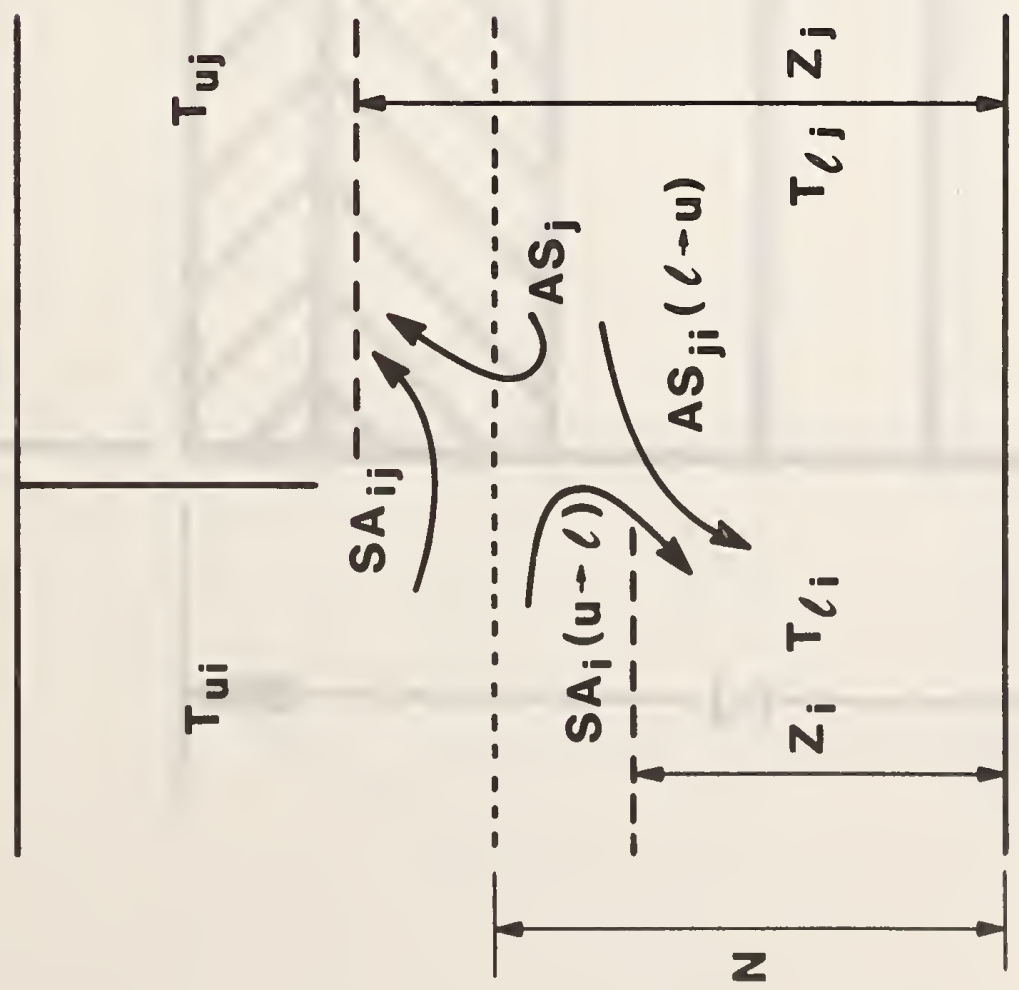

(1) 


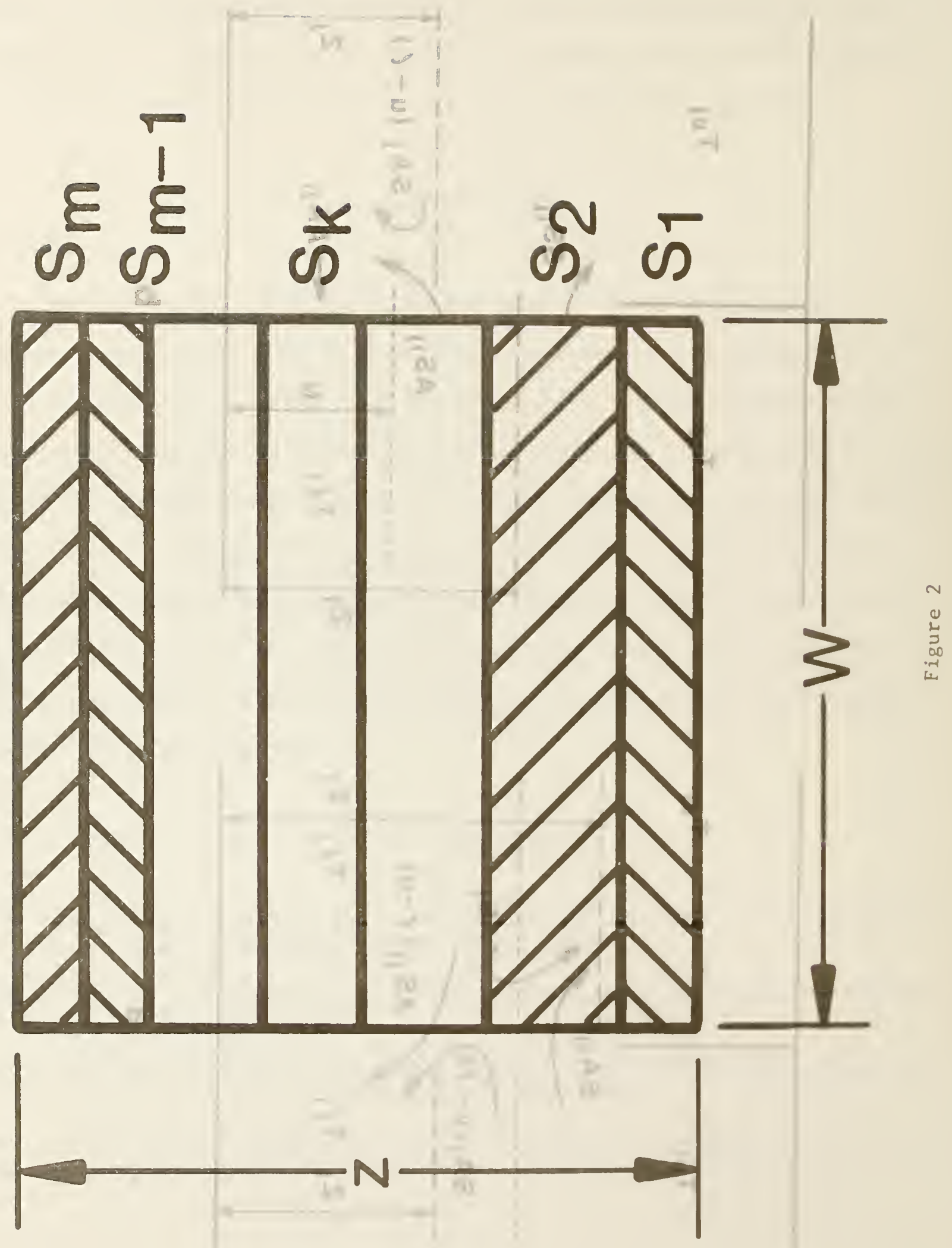




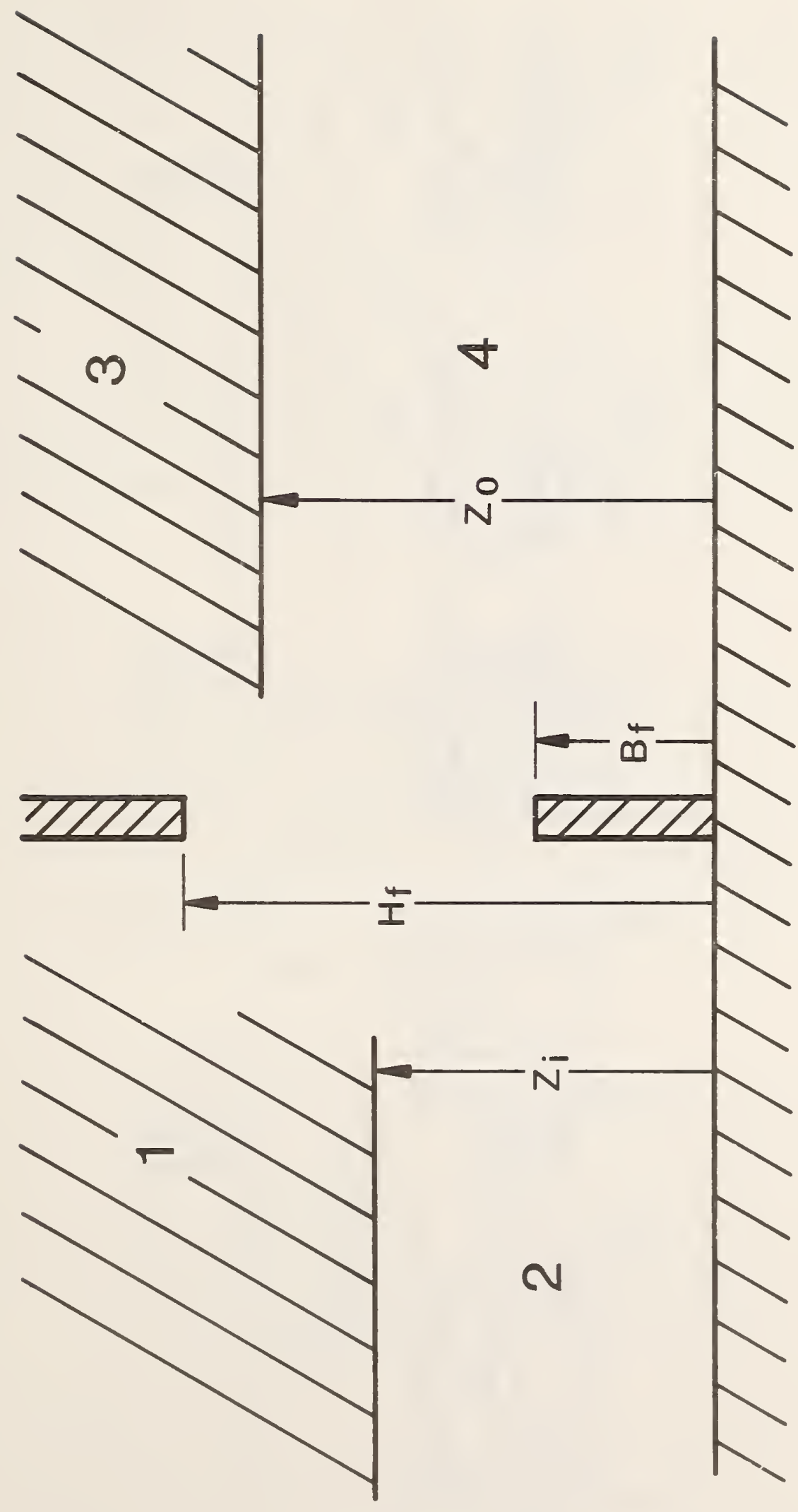

$\underbrace{n}_{\substack{\infty \\ 0}}$ 

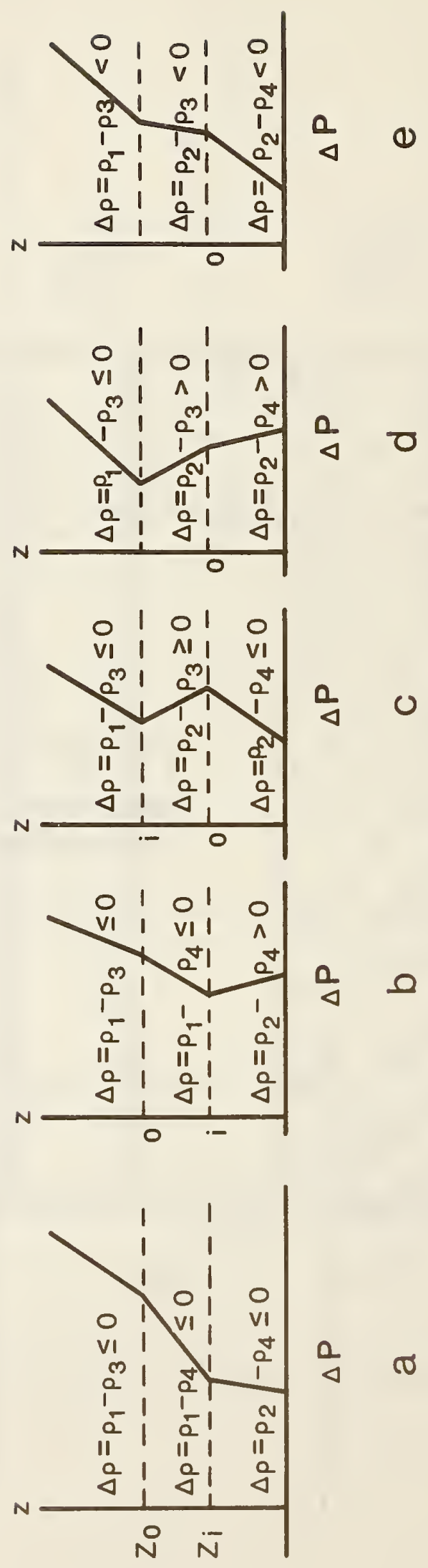


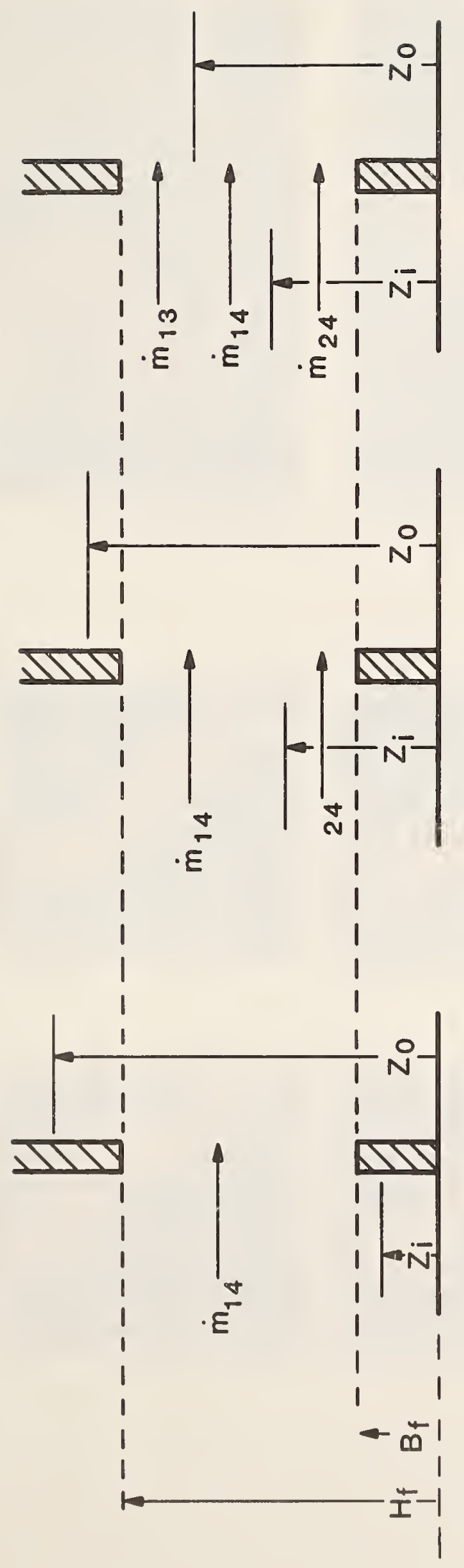

in 


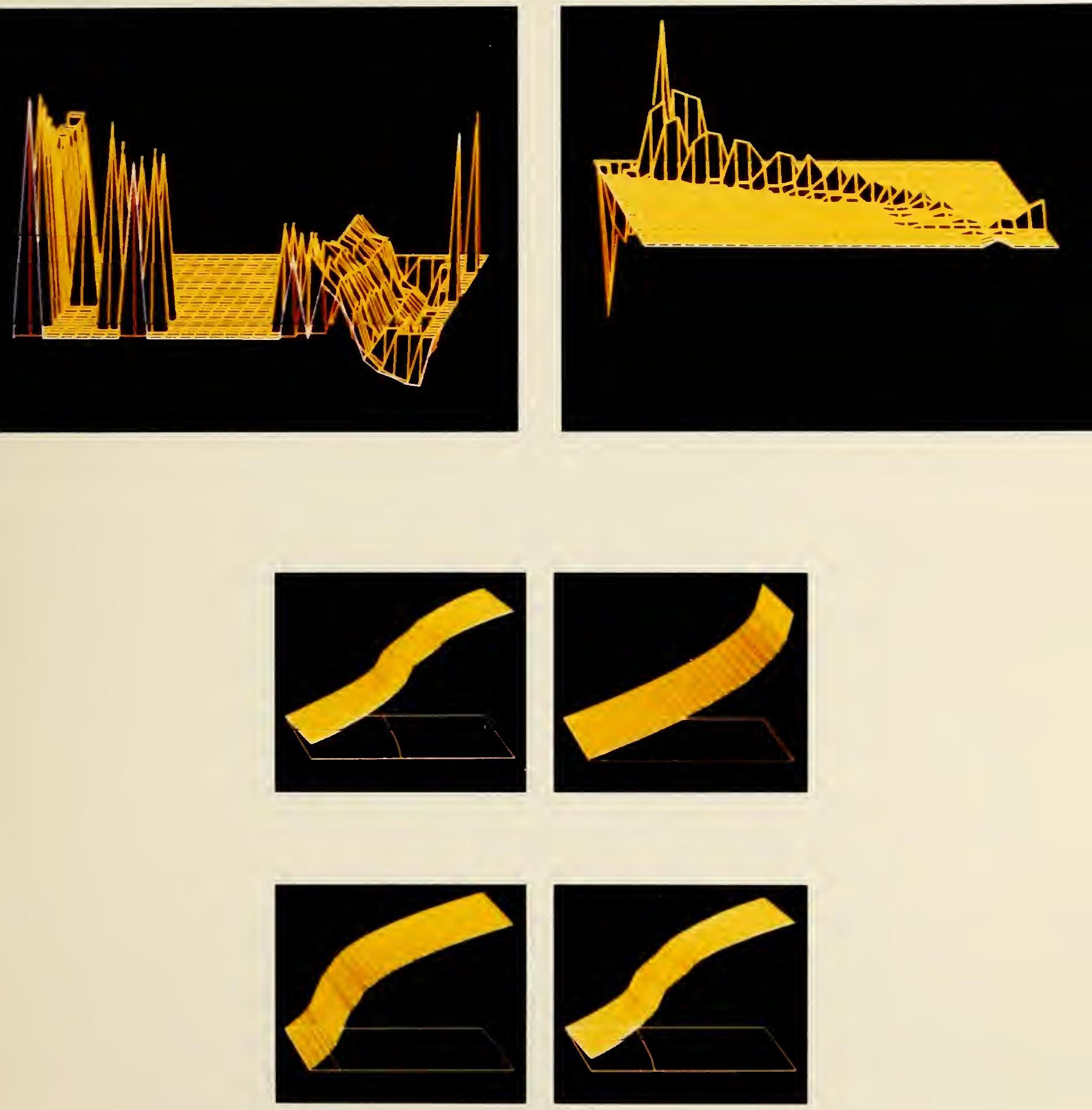

NBS-114A (REV. 2-8C)

U.S. DEPT. OF COMM.

BIBLIOGRAPHIC DATA

SHEET (See in structions)

\begin{tabular}{l|l|l}
\hline $\begin{array}{l}\text { 1. PUBLICATION OR } \\
\text { REPORT NO. }\end{array}$ & 2. Performing Organ. Report No. & 3. Publication Date \\
NBSIR-86/3329 & & May 1986 \\
\hline
\end{tabular}

4. TITLE AND SUBTITLE

Buoyancy Driven Flow as the Forcing Function of Smoke Transport Models

5. AUTHOR(S) Walter W. Jones, Xavier Bodart

6. PERFORMING ORGANIZATION (If joint or other than NBS, see instructions)

7. Contracu Grant No.

NATIONAL BUREAU OF STANDARDS

DEPARTMENT OF COMMERCE

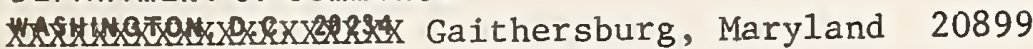

8. Type of Report \& Period Covered IR Final

9. SPONSORING ORGANIZATION NAME AND COMPLETE ADDRESS (Street, City, State, ZIP)

10. SUPPLEMENTARY NOTES

[Document describes a computer program; SF-185, FIPS Software Summary, is attached.

11. ABSTRACT (A 200-word or less factual summary of most significant information. If document includes a significant bibliography or literature survey, mention it here)

Flow at vents is the major driving force in smoke transport models. The precision with which we can calculate these flows determines to a great extent how accurately we can model buoyant flow and the inherent speed of the models. This report describes some of the problems encountered in calculating these flows, and gives a general algorithm for their calculation.

12. KEY WORDS (Six to twelve entries; alphabetica! order; capitalize only proper names; and seporate key words by semicolons)

fire models; numerical methods; smoke movement; zone models

13. AVAILABILITY

X] Unlimited

$\square$ For Official Distribution. Do Not Release to NTIS

$\square$ Order From Superintendent of Documents, U.S. Government Printing Office, Washington, D.C. 20402.

14. NO. OF

PRINTED PAGES

26

15. Price

X] Order From National Technical Information Service (NTIS), Springfield, VA. 2216I 


